\title{
El difícil equilibrio entre eficiencia energética y conservación de los valores patrimoniales en edificios históricos
}

La gestión eficiente de la energía en el patrimonio arquitectónico es un tema plenamente actual, que surge del consenso social y político sobre la necesidad de reducir progresivamente el consumo energético de los edificios. El texto que presentamos, a propósito de unas jornadas organizadas para finales de este año 2013, reflexiona sobre la necesaria búsqueda de un equilibrio entre las consideraciones de la eficiencia energética, la imprescindible conservación del patrimonio arquitectónico y la satisfacción de las necesidades de los ocupantes. Sus autores forman parte de un equipo de investigadores de la Universidad Politécnica de Cataluña que está desarrollando un proyecto de investigación al respecto.

José Luis González Moreno-Navarro, Alicia Dotor Navarro, Jordi Morros Cardona, Joan Olona Casas, Belén Onecha Pérez

| Universitat Politècnica de Catalunya

URL de la contribución <www.iaph.es/revistaph/index.php/revistaph/article/view/3393>

A partir de la primera crisis energética de los años 70 los edificios de nueva construcción deben estar concebidos y construidos normativamente de forma que su consumo energético sea reducido. Esta exigencia se incrementó sustancialmente a partir del año 2006, con la progresiva entrada en vigor del Código Técnico de la Edificación. No obstante, los edificios con valores patrimoniales quedan exentos del cumplimiento de los requerimientos de eficiencia energética. También la más reciente directiva europea sobre eficiencia energética (Directiva 2012/27/ UE) incide sobre todos los edificios exceptuando los bienes culturales inmuebles.

A pesar de ello, se está extendiendo progresivamente por Europa la opinión de que los edificios patrimoniales no pueden quedar completamente al margen de la voluntad de adecuación a la sostenibilidad energética, siendo los propietarios y gestores de edificios patrimoniales los principales interesados.

Pero esta voluntad supone a menudo un conflicto entre los procedimientos contemporáneos para resolver los requerimientos de eficiencia energética y la conservación de los valores patrimoniales. Esto se debe a que los criterios actuales de diseño de las instalaciones y las formas de actuar de los usuarios están enfocados fundamentalmente a edificios de nueva construcción y resultan de muy difícil, o incluso imposible, integración en edificios históricos.
Sin duda, la mayor dificultad que se nos presenta para mejorar el comportamiento energético de los edificios patrimoniales es que este objetivo requiere de un conocimiento profundo de su comportamiento real. Estos edificios cuentan con unos sistemas constructivos ligados a modos de vida y sistemas de calefacción y refrigeración totalmente diferentes a los actuales, siendo en la actualidad su conocimiento bastante escaso, principalmente teórico, y mayoritariamente de tipos edificatorios diferentes a los habituales en nuestro territorio.

La búsqueda de un equilibrio entre los imperativos de la eficiencia energética, la imprescindible conservación del patrimonio arquitectónico y la satisfacción de las necesidades de los ocupantes no es tarea fácil. Resulta imprescindible establecer un diálogo entre las soluciones tecnológicas, los valores culturales y los requerimientos de confort de los usuarios, haciendo partícipe al conjunto de los agentes involucrados: arquitectos, arquitectos técnicos, ingenieros, restauradores, administraciones, inversores, gestores $y$, especialmente, los usuarios finales.

Con este objetivo un equipo de investigadores de la Universidad Politécnica de Cataluña estamos desarroIlando un proyecto de investigación sobre mejora de la eficiencia energética del patrimonio cultural inmueble centrado en el estudio del comportamiento de casos 

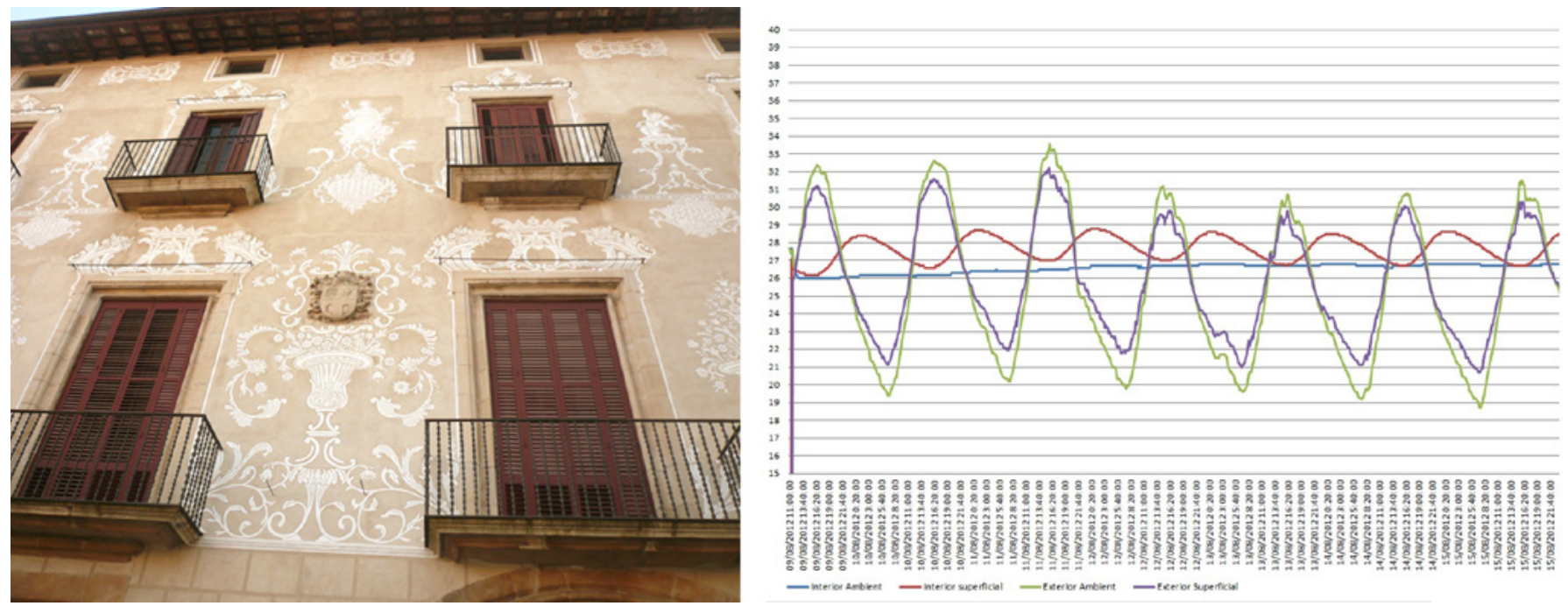

Imagen de una casa del siglo XVIII en Vic (Barcelona) junto al gráfico de monitorización térmica durante una semana del mes de agosto de 2012, en la cual se refleja el contraste entre la temperatura ambiental interior (azul), superficial interior (rojo), superficial exterior (violeta) y ambiental exterior (verde) | foto equipo redactor

reales. Esta investigación pretende elaborar una metodología de actuación analizando cuatro aspectos fundamentales: el diagnóstico energético respecto a la demanda y el rendimiento, el comportamiento energético a partir de la monitorización de los edificios, su consumo energético respecto a indicadores, y el grado de confort de los usuarios.

A tal efecto se han seleccionado una serie de edificios emblemáticos, de diversas épocas históricas y con soluciones constructivas diferentes, que permitan identificar la problemática propia en cada uno de los casos. En un primer estadio se requiere de un conocimiento mínimo de las características fundamentales arquitectónicas, patrimoniales y energéticas de los edificios, de manera que se pueda plantear su monitorización energética de manera óptima para realizar una diagnosis con el máximo rigor. En una segunda fase se trata de caracterizar los edificios escogidos, a partir de la información obtenida de la monitorización y posterior diagnosis, des de varios puntos de vista que incluyen desde los valores patrimoniales, a parámetros y requisitos energéticos. Finalmente se pretende desarrollar un análisis crítico y comparativo de los datos, que permita plantear una metodología de actuación en relación a los aspectos anteriormente mencionados.
Hay que diferenciar la motivación inicial del planteamiento energético por parte de los promotores, en función de si se pretende únicamente acreditar el estado energético del edificio a efectos de una transacción inmobiliaria, o bien si se requiere un aumento del confort ambiental, una reducción del gasto, del consumo, o de la demanda, una mejora de la relación entre el confort y el gasto, o combinaciones de estas posibilidades. También hay que considerar si la motivación inicial del planteamiento energético de los bienes culturales inmuebles se debe a un cambio de uso del edificio, o bien se pretende mantener el uso existente. A su vez, cada uno de estos aspectos requiere enfoques específicos por parte de los distintos agentes intervinientes en los edificios históricos, refiriéndonos fundamentalmente a los gestores 0 promotores, a los técnicos, o bien a los usuarios de la arquitectura.

Los resultados de esta investigación se presentarán dentro de la XXXVI edición de las Jornadas internacionales sobre la intervención en el patrimonio arquitectónico, organizadas por la Agrupación de Arquitectos para la Defensa e Intervención en el Patrimonio Arquitectónico (AADIPA) del Colegio de Arquitectos de Cataluña, que se celebrarán en Barcelona del 12 al 15 de diciembre de 2013.

Para más información: http://www.coac.net/aadipa/bloc/ 